\title{
Titanium Acetylacetonate as an Excellent Ion-Carrier in Construction of Iodide Sensor
}

\author{
Mohammad Reza Ganjali, Azadeh Daftari, Farhang Mizani, and Masoud Salavati-Niasari \\ Department of Chemistry, Tehran Lniversity, Tehran 14155-6455, Iran \\ - Department of Chemistry: Kashan Lniversity, Kashan, Iran \\ Recerved Altgust 30, 2002
}

\begin{abstract}
Titanium acetylacetonate was used in the construction of a PVC-based membrane electrode. This sensor shows very good selectivity for iodide ion over a wide variety of conmon inorganic and organic anions. It exhibits Nernstian behavior with a slope of $59.1 \mathrm{mV}$ per decade. The working concentration ranges of the sensor are 1.0 $\times 10^{-1}-5.0 \times 10^{-6} \mathrm{M}$ with a detection limit of $3.0 \times 10^{-6} \mathrm{M}$. The response time of the sensor is very fast $(<8 \mathrm{~s})$. and can be used for at least twelve weeks in the $\mathrm{pH}$ range of 4.0-9.2. The best performance was obtained with a membrane composition of $30 \%$ PVC. $65 \%$ dibutylphthalate. $3 \%$ titanium acetylacetonate and $2 \%$ hexadecyltrimethylammonium bromide. The proposed sensor was successfully applied as an indicator electrode for titration of iodide with silver ion
\end{abstract}

Key Words : Titanium acety lacetonate. Iodide sensor. Potentiometry. PVC

\section{Introduction}

The quick determination of minute quantities of ionic species by simple methods is of special interest in analytical chemistry: Potentiometric detection based on ion-selective electrodes (ISEs) offers the advantages of speed and ease of preparation and procedures. relatively fast response. reasonable selectivity thorough judicious choice of the membrane active materials. wide linear dynamic range. and low cost. These characteristics have inevitably led to the preparation of numerous sensors for several ionic species. and the list of available electrodes has grown substantially over the past years. ${ }^{1}$

Although the majority of the approximately 60 ions for which ionophore based polymeric membrane ion-selective electrodes have been described up to now are for cations. ${ }^{1.2}$ a series of new anion selective electrodes was also introduced recently. ${ }^{3-8}$ a result of the growing interest in the specific interaction between central metals of organometallic compounds and primary anions.

We have recently introduced several PVC-based sensors for different anions. such as $\mathrm{I}^{-5.10} \mathrm{SCN}^{-11.12} \mathrm{SO}_{4}{ }^{-2}$. 13-15 $\mathrm{HPO}_{4}{ }^{2-16}$ To the best of our knowledge there is no report on the application of titanium complex in the construction of anioninselective electrodes. In this work. we report the use of a titanium acetylacetonate (TAA) (Fig. 1) as an excellent

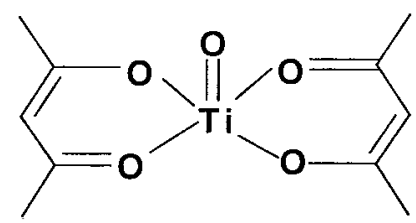

Figure 1. Structure of titanium acetylacetonate.

\footnotetext{
*Corresponding author: Fax: +98-21-640-5141; e-mail: ganjali âk khavamut.ac.ir
}

neutral ion-carrier for preparation of highly selective iodide PVC-based membrane sensors.

\section{Experimental Section}

Reagent. Reagent grade dibuțll phthalate (DBP), $o$-nitrophenyloctyl ether (NPOE), benzyl acetate (BA), tetrahydrofuran (THF), hexadecyltrimethylammonium bromide (HTAB) and high relative molecular weight PVC were purchased from Merck chemical company (Germany. Frankfurter Str. 250 ) and used as received. Reagent grade potassium salts of all anions used (all from Aldrich. Aldrich chemical company. Inc. Milwaukee. Wisconsin 53233 USA) were of highest purity available and used without any further purification except for vacuum drying over $\mathrm{P}_{2} \mathrm{O}_{5}$. Titanium acetylacetonate (TAA) and all other reagents needed were purchased from Merck and used as received. Triply distilled de-ionized water was used throughout.

Electrode Preparation. The general procedure to prepare the PVC membrane was to mix thoroughly. $30 \mathrm{mg}$ of PVC. 3 $\mathrm{mg}$ of TAA. $2 \mathrm{mg}$ of HTAB and $65 \mathrm{mg}$ of DBP. Then the mixture was dissolved in $3 \mathrm{~mL}$ of dry freshly distilled THF. The resulting clear mixture was evaporated slowly until an oily concentrated mixture was obtained. A Pyrex tube $(5 \mathrm{~mm}$ i.d.) was dipped into the mixture for about $5 \mathrm{~s}$. so that a nontransparent membrane of about $0.3 \mathrm{~mm}$ thickness was formed. The tube was then pulled out from the mixture and kept at room temperature for about $2 \mathrm{~h}$. The tube was then filled with internal solution $\left(1.0 \times 10^{-3} \mathrm{M} \mathrm{KI}\right)$. The electrode was finally conditioned for 24 h by soaking in a solution containing $1.0 \times 10^{-3} \mathrm{M} \mathrm{KJ}$.

Potential Measurements. All emf measurements were carried out with the following assembly:

$\mathrm{Ag}-\mathrm{AgCl} \mid$ internal solution $\left(1.0 \times 10^{-3} \mathrm{M} \mathrm{KI}\right) \mid \mathrm{PVC}$ membrane | test solution $|\mathrm{Ag}-\mathrm{AgCl}| \mathrm{KCl}$ (satd)

A Corning ion analyzer $250 \mathrm{pH} / \mathrm{mV}$ meter was used for 


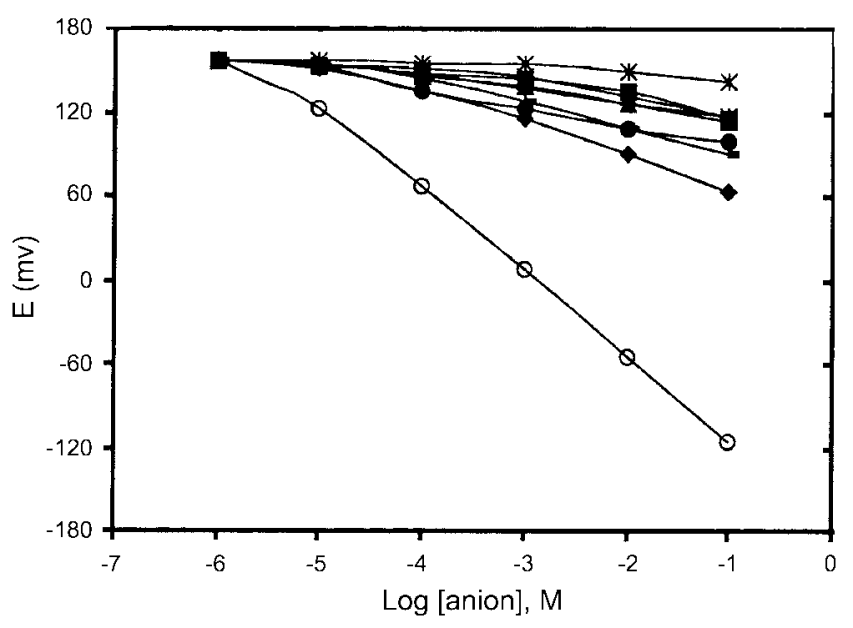

Figure 2. Potential responses of different ionselective electrodes based on titaniunn. Acetylacetonate: ( $\rightarrow$ - Cyanide) ( $\rightarrow$ Nitrate), ( $\leftarrow$ Nitrite), ( $\rightarrow$ Thiocyanate). ( + Acatate), (* Chloride), (- Iodide), ( - Bromide), ( - Perchlorate), $(\mp$ Salicylate).

the potential measurements at $25 \pm 0.1^{\circ} \mathrm{C}$. The emf observations were made relative to a double-Junction saturated calomel electrode (SCE. Philips) with the chamber filled with an ammonium nitrate solution. Activities were calculated according to the Debre-Huckel procedure. ${ }^{17}$

\section{Results and Discussion}

In preliminary experiments. TAA was used as an ion carrier in construction of ion-selective sensors for some common anions. The potential responses of these electrodes are shown in Figure 2. As can be seen, the membrane sensor displayed remarkable selectivity for $\mathrm{I}^{-}$ions over other anions. Such anti-Hofmeister selectivity is believed to be the result of a specific interaction between the central metal ion and iodide ions.

The preferential response toward $\mathrm{I}^{-}$is believed to be associated with the coordination of iodide with the central metal of the carrier. The substantial increase in absorbance at $251.6 \mathrm{~nm}$ after the contact of the carrier solution with iodidecontaining phase suggested that the absorbing species had increased in size and axial coordination was thought to take place.

It is well understood that the sensitivity and selectivity of the ion-selective electrodes depend not only on the nature of the ion-carrier used. but also significantly on the membrane composition and the properties of solvent mediators and additives used.-14 Thus the influences of the membrane composition. nature of solvent mediator and additive on the response characteristics of the $\mathrm{I}^{-}$sensor were investigated. and the results are shown in Table 1 and Figure 3 . As it is seen. among three different plasticizers used the use of DBP resulted in the best response characteristics (no. 5). whereas the use of BA and NPOE resulted in a pronounced reduction in the slope of the electrode response. Table 1 shows that the optimum amount of ionosphere TAA is $3 \%$.

It is well known that the cationic additives improve the
Table 1. Optimization of membrane ingredients

\begin{tabular}{cccccc}
\hline \multirow{2}{*}{$\begin{array}{c}\text { Number of } \\
\text { membrane }\end{array}$} & \multicolumn{5}{c}{ Composition wt\% } \\
\cline { 2 - 6 } & PVC & Plastisizer & TAA & HTAB & Slope $^{a}$ \\
\hline 1 & 30 & DBP, 68 & - & 2 & $-3.5 \pm 0.6$ \\
2 & 30 & DBP, 67 & 3 & - & $-37.7 \pm 0.2$ \\
3 & 30 & $\mathrm{DBP}_{5} 65$ & 5 & - & $-35.2 \pm 0.5$ \\
4 & 30 & $\mathrm{DBP}, 66$ & 2 & 2 & $-52.3 \pm 0.3$ \\
5 & 30 & $\mathrm{DBP}, 65$ & 3 & 2 & $-59.1 \pm 0.3$ \\
6 & 30 & $\mathrm{DBP}, 66$ & 4 & 2 & $-56.4 \pm 0.4$ \\
7 & 30 & $\mathrm{DBP}, 64$ & 3 & 3 & $-59.0 \pm 0.5$ \\
8 & 30 & $\mathrm{NPOE}, 64$ & 3 & 3 & $-42.0 \pm 0.6$ \\
9 & 30 & $\mathrm{NPOE}, 62$ & 5 & 3 & $-41.5 \pm 0.4$ \\
10 & 30 & $\mathrm{BA}, 65$ & 3 & 2 & $-38.3 \pm 0.2$ \\
\hline
\end{tabular}

Results are based on triplicate measurements.

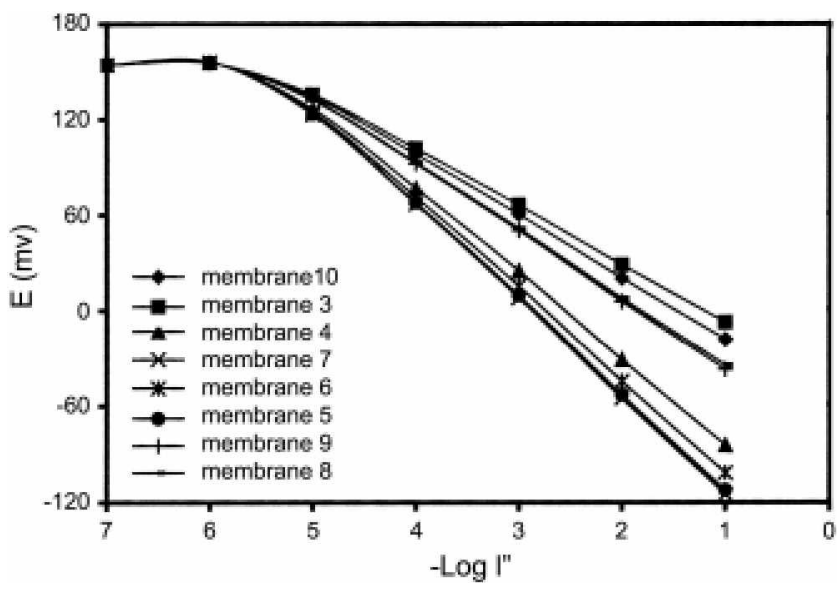

Figure 3. Potential response of iodide sensors with different compositions in $\mathrm{pH} 7$.

EMF response of the anion selective electrodes. ${ }^{11-15}$ As it is obvious from Table 1. the presence of HTAB in the menbrane composition (no. 4-9) increases the sensitivity of the sensors. The membrane (no. 5) with an optimum mole ratio HTAB/TAA of about 0.85 revealed a Nernstian response to the concentration of iodide. By addition of more HTAB to the membrane, the selectivity of the electrode for high lipophilic anions such as perchlorate and salicylate will increase by co-extraction of ion-pair formation between perchlorate or salicylate anions and hexadecyltrimethỵlammonium cation.

Table 1. shows that a PVC membrane electrode with a PVC : DBP : TAA : HTAB percent ratio of $30: 65: 3: 2$ resulted in the Nernstian behavior of the membrane electrode over a very wide concentration range (Fig. 3).

The critical response characteristics of the proposed sensor were assessed according to IUPAC recommendations. ${ }^{18}$ The EMF response of the polymeric membrane (Fig. 4) indicates a Nernstian slope of $-59.1 \pm 0.5 \mathrm{~m} V$ per decade over a very wide concentration of iodide from $1.0 \times 10^{-1}-5.0 \times 10^{-6} \mathrm{M}$. The limit of detection. defined as the concentration of iodide obtained when extrapolating the linear region of calibration graph to the base line potential. is $3.0 \times 10^{-6} \mathrm{M}$

The influence of the $\mathrm{pH}$ of the test solutions $\left(1.0 \times 10^{-3} \mathrm{M}\right.$ 


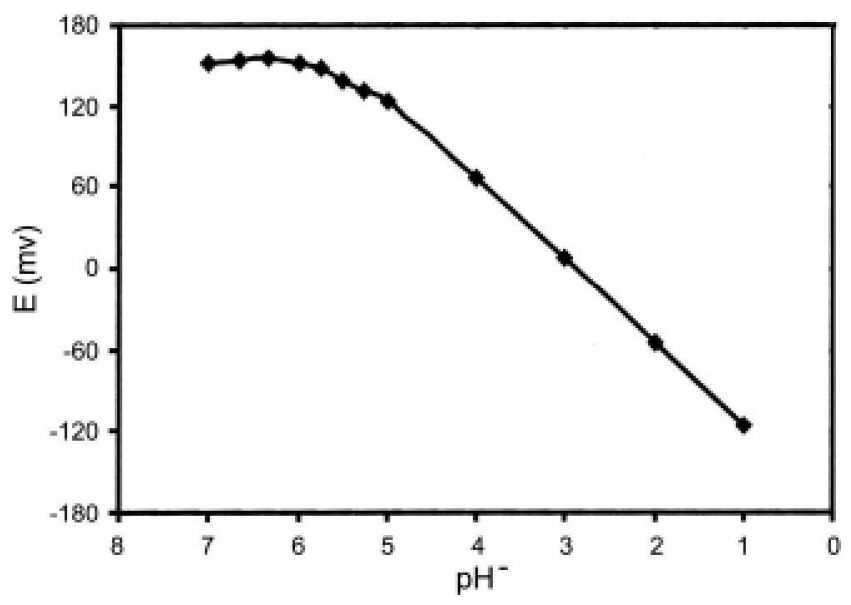

Figure 4 . Calibration curves of iodide electrode based on titanium acetylacetonate in $\mathrm{pH} 7$.

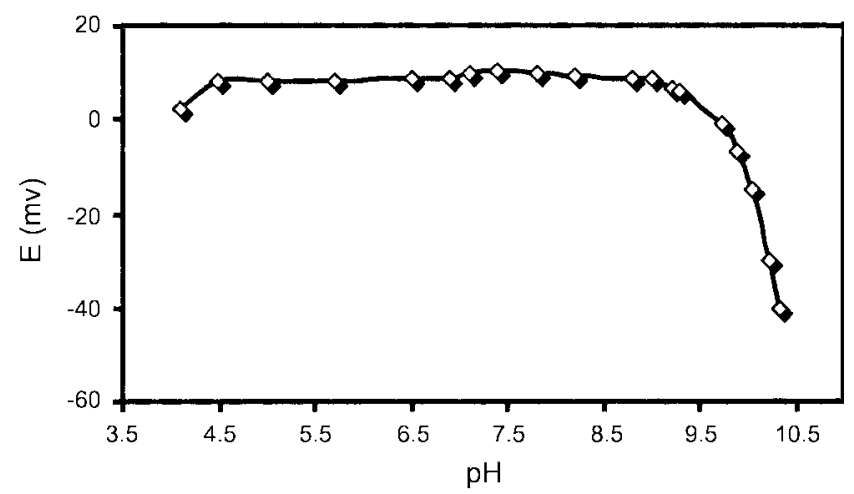

Figure 5. Effect of $\mathrm{pH}$ of the test solution on the potential response of the iodide sensor.

of $\mathrm{I}^{-}$) on the potential responses of the membrane sensor was tested in the $\mathrm{pH}$ range $4.0-10.5$, and the results are shown in Figure 5. As can be seen. potentials remain constant in the $\mathrm{pH}$ range 4.0-9.2. At higher alkaline media. the potential changed sharply; most probably due to the response of the sensor to both iodide and hydroxide ions.

Dynamic response time is an important factor for any ionselective electrode. In this study. the practical response time was recorded by immediate changing of $\mathrm{I}^{-}$concentration from $1.0 \times 10^{-5}$ to $1.0 \times 10^{-1} \mathrm{M}$. The actual potential-time trace is shown in Figure 6 . As can be seen. in whole concentrations range. the sensor reaches the equilibrium response in a very short time $(<8 \mathrm{~s})$.

Lifetime studies were based on monitoring the change in the slope of the electrode with time. After twelve weeks. a very slight decrease in slope (from $-59.1 \pm 0.4$ to $-56.5 \pm 0.6$ $\mathrm{mV}$ decade ${ }^{-l}$ ) of the sensor was observed.

One of the most important characteristic of any ion-selective electrode is its relative response to the primary ion over other ions present in solution. which is expressed in terms of potentiometric selectivity coefficients. Potentiometric selectivity coefficients $\left(\mathrm{K}_{\mathrm{pot}}\right)$. describing the preference by the membrane for an interfering ion $\left(\mathrm{A}^{\mathrm{n}}\right)$ relative to $\mathrm{I}^{-}$. were determined by the matched potential method. ${ }^{1 / 9}$ The results of selectivity coefficient data with different compositions are

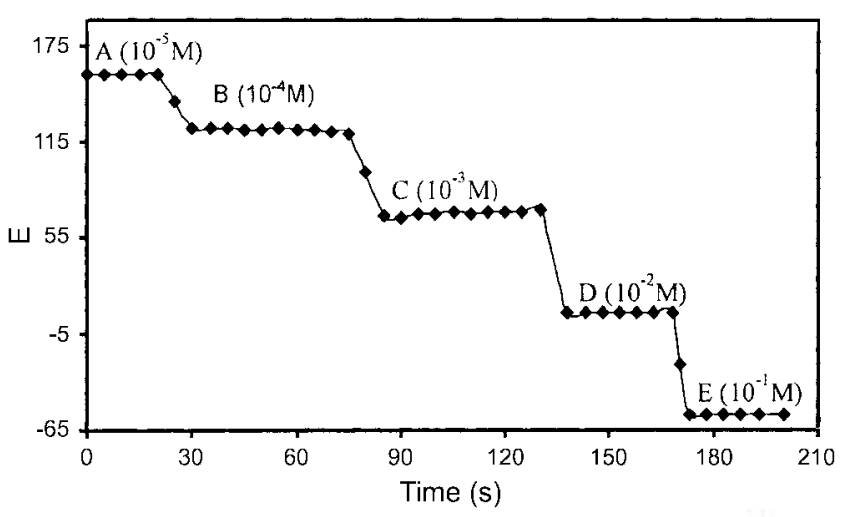

Figure 6. Dynamic response time of the iodide electrode for step changes in concentration of $\mathrm{I}^{-}$: (A) $1.0 \times 10^{-5} \mathrm{M}$, (B) $1.0 \times 10^{-4} \mathrm{M}$.

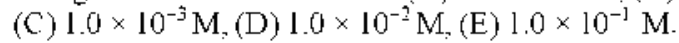

Table 2. Selectivity coefficients of various intertering anions for the best membrane sensors

\begin{tabular}{ccccc}
\hline & \multicolumn{4}{c}{$K_{\Gamma j}^{p o t}$} \\
\cline { 2 - 5 } Foreign ion & \multicolumn{4}{c}{ Membrane number } \\
\cline { 2 - 5 } & 5 & 6 & 7 & 8 \\
\hline $\mathrm{SCN}^{-}$ & $7.90 \times 10^{-4}$ & $9.01 \times 10^{-4}$ & $8.37 \times 10^{-4}$ & $1.41 \times 10^{-3}$ \\
$\mathrm{ClO}_{4}^{-}$ & $4.45 \times 10^{-4}$ & $5.08 \times 10^{-4}$ & $4.73 \times 10^{-4}$ & $6.42 \times 10^{-4}$ \\
$\mathrm{CN}^{-}$ & $3.51 \times 10^{-4}$ & $4.00 \times 10^{-4}$ & $3.72 \times 10^{-4}$ & $5.05 \times 10^{-4}$ \\
$\mathrm{Br}^{-}$ & $2.81 \times 10^{-4}$ & $3.20 \times 10^{-4}$ & $2.98 \times 10^{-4}$ & $4.05 \times 10^{-4}$ \\
$\mathrm{NO}_{2}^{-}$ & $2.21 \times 10^{-4}$ & $2.52 \times 10^{-4}$ & $2.34 \times 10^{-4}$ & $3.18 \times 10^{-4}$ \\
$\mathrm{NO}_{3}^{-}$ & $1.41 \times 10^{-4}$ & $1.61 \times 10^{-4}$ & $1.49 \times 10^{-4}$ & $2.03 \times 10^{-4}$ \\
$\mathrm{CH}_{3} \mathrm{COO}^{-}$ & $1.12 \times 10^{-4}$ & $1.28 \times 10^{-4}$ & $1.19 \times 10^{-4}$ & $1.61 \times 10^{-4}$ \\
$\mathrm{Cl}^{-}$ & $3.16 \times 10^{-4}$ & $3.60 \times 10^{-5}$ & $3.35 \times 10^{-5}$ & $4.55 \times 10^{-3}$ \\
Salicylate & $3.28 \times 10^{-4}$ & $3.55 \times 10^{-4}$ & $3.42 \times 10^{-4}$ & $3.88 \times 10^{-4}$ \\
\hline
\end{tabular}

Table 3. Comparison of serious interfering ions of different I- ISEs

\begin{tabular}{cc}
\hline Reference & Serious intertering ion \\
\hline 21 & $\mathrm{SCN}^{-}$ \\
22 & $\mathrm{Br}^{-}, \mathrm{SCN}^{-}, \mathrm{ClO}_{+}^{-}$ \\
20 & $\mathrm{SCN}^{-}, \mathrm{NO}_{2}^{-}, \mathrm{ClO}_{+}^{-}$ \\
23 & $\mathrm{Br}^{-}, \mathrm{SCN}^{-}, \mathrm{ClO}_{+}^{-}, \mathrm{NO}_{2}^{-}$ \\
This work & - \\
\hline
\end{tabular}

given in Table 2. From the data in Table 2, it is obvious that the selectivity coefficients are in the order of $7.90 \times 10^{-1}$ or smaller. which seems to indicate that these anions have negligible disturbance on the functioning of the $\mathrm{I}^{-}$ion-selective electrode.

In Table 3. most interfering ions (with selectivity coefficients $>2.0 \times 10^{-3}$ ) of the proposed electrode are compared with those of the previously reported iodide sensors based on nickel(II) tetraazaanulene. ${ }^{20}$ silver(I) thiourea complex. ${ }^{21}$ silver(I) complex of $n$-thiocarbamoy limine-derivatives. ${ }^{2-}$ and transitional metal chelates of bis-furfural-seni-o-tolidine. ${ }^{23}$ As seen from Table 3, the proposed sensor in terms of selectivity is superior to those reported $\mathrm{I}^{-}$ion-selective electrodes.

The proposed membrane iodide electrode was successfully used as an indicator electrode in potentiometric titration of iodide ion solution $\left(1.0 \times 10^{-4} \mathrm{M}\right)$ with the silver ion $(1.0 \times$ 


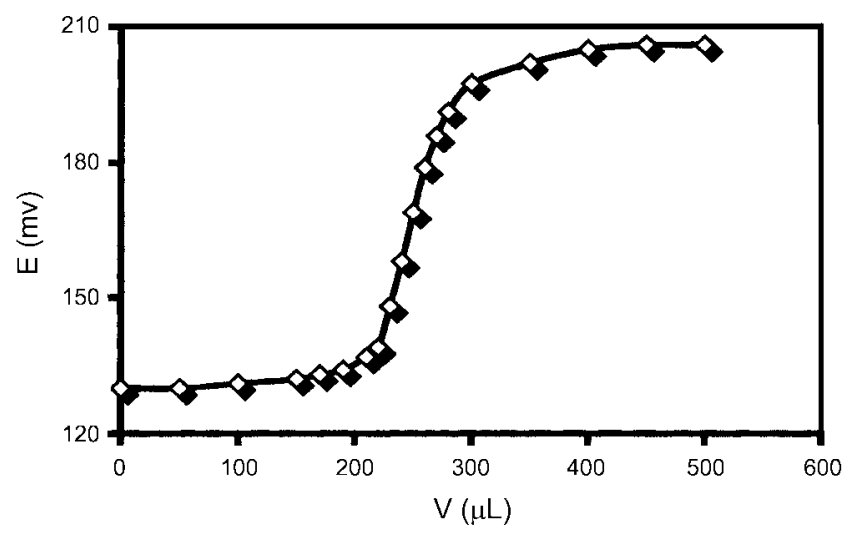

Figure 7. Potentiometric titration curve of $25.0 \mathrm{~mL} 1.0 \times 10^{-4} \mathrm{M}$ solution of $\mathrm{I}^{-}$with $1.0 \times 10^{-2} \mathrm{M}$ of $\mathrm{Ag}^{+}$

$10^{-2} \mathrm{M}$ ). The result of titration is shown in Figure 7. indicating that the amount of $\mathrm{I}^{-}$can be determined with the electrode.

Acknowledgment. We would like to thank the University of Teluran Research Council for its financial support.

\section{References}

1. Bulhlmann, P: Pretsch, E: Backer, E. Chen. Rev: 1998. $98,1593$.

2. Bakker. E.: Buhlmant. P.: Pretsch. E. Chem. Rev 1997. 97. 3083

3. Amini. M. K.: Shahrokhian. S.: Tangestaninejad. S. Anal Chim. Acta 1999, 402.137.

4. Li, Z. Q: Wu. Z. Y: Yuan, R.: Ying, M.: Shen. G. L.: Yus. R. Q. Electrochint Acto 1999. 44, 2543.

5. Amemiya. S.: Bullnlmann. P. Unnezawa. Y: Tagessar R. C.: Bunts. D. H. Anal Chem. 1999.71. 1049

6. Channiotaksi. N. A.: Chasser. A. M: Meyerhotf. M. E. Afral.
Chent $1998,60,185$

7. Meyerhoff. M. E.: Pranitis. D. M.: Ym. H. S.: Chaniotakis. N. A.: Park. S. B. Am. Chem. Soc. Symposium Series 1989. 403.26.

8. Yuan. R.: Chai. Y.: Liu. D.: Gao. D.: Li. J.: Yu. R. Anal. Chem 1993. 65,2572 .

9. Poursaberi. T:; Hosseini. M: Taghizadeh. M.: Pirelahi, H.; Shamsipur. M.; Ganjali, M. R. Hichochent. J. 2002. 72. 77.

10. Ganjali. M. R.: Poursaberi. T.: Hosseini. M.: Salavati-Niasari. M.: Yousefi. M.: Shamsipur. M. Anal. Sci. 2002. 18. 289.

11. Poursaberi. T.: Salavati-Niasari. M.: Khodabakihsh. S.: HajiaghaBabaei. L.: Shamsipur. M.: Yousefi. M.: Rouhanii. S.: Ganjali. M. R. Anal. Lett. $2001.3+2621$.

12. Ganjali, M. R.; Poursaberi. T,; Basiripour, F.; Salavati-Niasar, M.: Youseti. M.: Shansipur. M.; Feresnius. J. Anal Chent 2001. 370. 1091 .

13. Shamsipur. M.: Yousefi. M.: Hosseini. M.: Ganjali. M. R.: Sharghi. H.: Naeni. H. Anal. Chem 2001. 73. 2869

14. Shamsipur. M: Yousefi, M.: Ganjali. M. R.: Poursaberi, T.: FaalRastgar. M. Sens. Actwotore. B 2002, 82, 105.

15. Ganjali, M. R.; Naji, L:; Poursaberi. T:; Taghizadeh, M.: Pirelahi, H.: Yousefi. M.: Yeganeh-Faal. A.: Shamsipur. M. Talanta 2002. in press.

16. Ganjali. M. R.: Mizani. F.: Enami. M.: Salavati-Niasari. M.: Shamsipur, M.; Yousefi, M.: Javanbakht. M. Electroonalysis 2002. in press.

17. Kamata. S: Bhale. A.: Fukunaga, Y: Murata, A. Anal. Chent. 1998. 60.2464

18. IUPAC Analytical Chemistry Division. Commission on Analytical Nomenclature Pure. Appl. Chem. 1976. 48. 127.

19. Umezawa, Y.; Umezawa. K.: Sato, H. Pure. Appl. Chem. 1995.67. 507.

20. Ying. M.; Yuan. R.: Zhang, X. M.: Song. Y.: Li, Z; Shen. G.: Yu. R. Andlyst 1997.122. 1143

21. El Amarani. F.: Garica-Raurich. T.: Sastre. A: Bever. L:: Florido. A. Anal Chim. Acta 1999. 402.129.

22. El A marani. F; Garica-Raurich. J.: Sastre, A.; Bever, L.; Florido. A. Anal. Chim. Acta 1996, 329. 247.

23. Li. Z:; Yuan. R.; Ying. M.: Song, Y.: Shen. G.; Yu, R. Anal. Lett 1997. 30.1455 . 